\title{
Potentials of Thermal Energy Storage Integrated into Steam Power Plants
}

\author{
Michael Krüger ${ }^{1, * \mathbb{D}}$, Selman Muslubas ${ }^{2}$, Thomas Loeper ${ }^{3}$, Freerk Klasing ${ }^{4}$, Philipp Knödler ${ }^{1}$ \\ and Christian Mielke ${ }^{3}$ \\ 1 German Aerospace Center (DLR), Institute of Engineering Thermodynamics, 70569 Stuttgart, Germany; \\ philipp.knoedler@dlr.de \\ 2 Chair of Environmental Process Engineering and Plant Design, University of Duisburg-Essen, \\ 45141 Essen, Germany; selman.muslubas@uni-due.de \\ 3 Siemens AG, Power and Gas Division, 91058 Erlangen, Germany; thomas.loeper@siemens.com (T.L.); \\ christian.mielke@siemens.com (C.M.) \\ 4 German Aerospace Center (DLR), Institute of Engineering Thermodynamics, 51147 Köln, Germany; \\ freerk.klasing@dlr.de \\ * Correspondence: Michael.Krueger@dlr.de
}

Received: 21 January 2020; Accepted: 22 April 2020; Published: 3 May 2020

\begin{abstract}
For conventional power plants, the integration of thermal energy storage opens up a promising opportunity to meet future technical requirements in terms of flexibility while at the same time improving cost-effectiveness. In the FLEXI- TES joint project, the flexibilization of coal-fired steam power plants by integrating thermal energy storage (TES) into the power plant process is being investigated. In the concept phase at the beginning of the research project, various storage integration concepts were developed and evaluated. Finally, three lead concepts with different storage technologies and integration points in the power plant were identified. By means of stationary system simulations, the changes of net power output during charging and discharging as well as different storage efficiencies were calculated. Depending on the concept and the operating strategy, a reduction of the minimum load by up to $4 \%$ of the net capacity during charging and a load increase by up to $5 \%$ of the net capacity during discharging are possible. Storage efficiencies of up to $80 \%$ can be achieved.
\end{abstract}

Keywords: coal power plants; TES; thermal energy storage

\section{Introduction}

The global trend in power generation is to reduce $\mathrm{CO}_{2}$ emissions by expanding renewable energies. According to World Energy Outlook 2017 [1], by 2040, two-thirds of global investment in the power sector is expected to go to renewable generation. Renewable power generation technologies have been adapted to mass production, so that electricity production costs are falling steadily. Competitive auctioning, grid feed-in promotion and clean energy financing are leading to an increasing share of renewable energy.

This increases the fluctuations in electricity generation and the classic division into base, medium and peak load is abolished, leaving largely only the renewable portion and the so-called residual load. This trend is accompanied by the expansion of grids, the increase of electricity storage capacities, the participation of renewable energy generation in grid control and residual load generation by conventional power plants for reliable electricity generation. While the residual load is minimized, the flexibility of residual load generation must be increased to cope with fluctuations in power generation and consumption and to ensure grid stability. 
For conventional power plants, the integration of thermal energy storage (TES) into the power plant process opens up a promising opportunity to meet future flexibility requirements and at the same time improve cost-effectiveness [2].

TES systems that have been implemented in coal-fired power plants in the past exclusively concern isolated solutions, such as the steam storage system in the Berlin-Charlottenburg power plant [3], or special supply conditions, such as the high-pressure storage system in the power plant near Vienna [4]. Even then, the integration of TES was aimed at increasing the flexibility of coal-fired power plants. The literature also contains examples of direct and indirect heat extraction in the feedwater section as well as high-pressure and low-pressure storage tanks in the steam section of power plants. One example is a concept presented by Jentsch et al. [5] of a displacement storage arranged parallel to the high-pressure preheating section. Other examples are the concepts developed by Li et al. [6] for the integration of cascade latent TES into a supercritical coal-fired power plant with different charging and discharging strategies. However, there are also studies that suggest innovative power plant concepts with storage facilities. The conceptual solutions mentioned there concern TES units as a separation of firing and steam generation and an integrated gasification combined cycle (IGCC) power plant with indirect steam generation via a TES system [7]. Another example is the high temperature thermal energy storage (HTTES) through additional thermodynamic cycle integrated at the boiler of the coal-fired power plant [8]. Apart from numerous district heat storage projects, e.g., in Mannheim [9] and Nuremberg [10], that have already been realized, the topic of high temperature heat storage in coal fired power plants is so far only being investigated theoretically in one project [11] other than the FLEXI-TES project.

Since 2017, a consortium of German public utilities and power plant suppliers as well as universities and research institutions (see Figure 1) has been working on integration concepts for thermal energy storage (TES) in order to tackle the aforementioned challenges posed by the German energy transition. The joint project FLEXI-TES (Power Plant Flexibilization by the use of TES) has the overall objective of making coal-fired steam power plants more flexible by integrating TES and is supported by the Federal Ministry of Economics and Energy (BMWi) over a period of three years with around $€ 2.4$ million. Technical goals are the evaluation of integration concepts in new and existing plants, the adaptation and further development of storage technologies as well as the elaboration of a cost-efficient and low-risk integration concept. The selection of suitable storage technologies, their integration and design, supplemented by stationary power plant simulations, form milestones of the concept phase until 2018. The subsequent detailed investigations of the identified lead concepts take place in the last two project years and include dynamic power plant simulations, detailed TES design, economic evaluations and a study on TES integration at a selected reference plant.
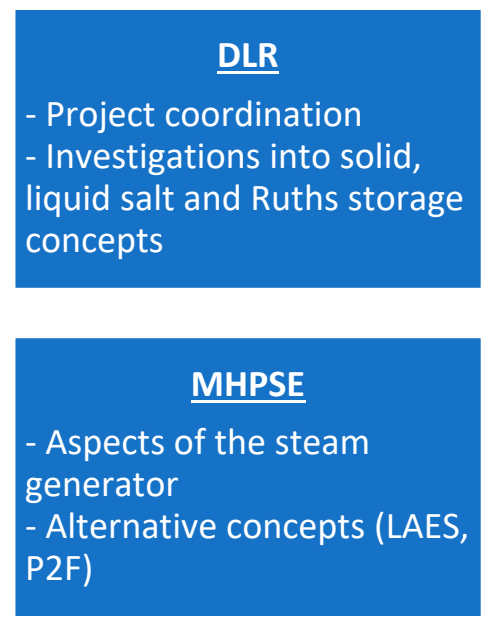
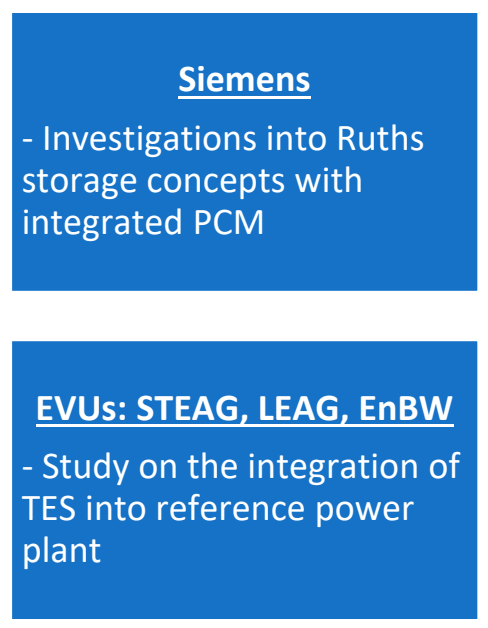
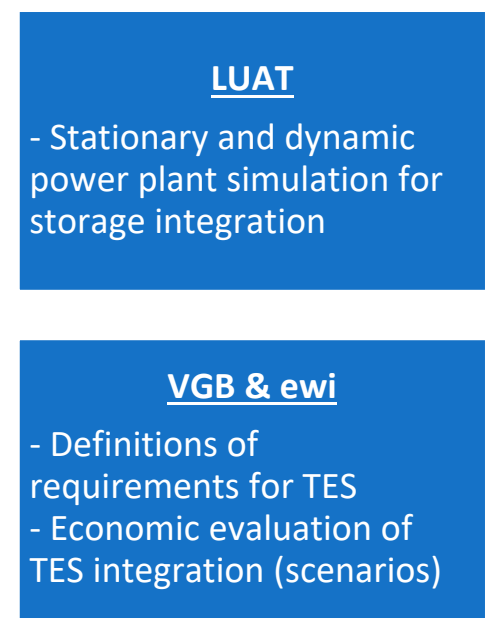

Figure 1. Project partners and work contents in the joint project FLEXI- TES. 
In this paper, suitable TES technologies, their modelling and stationary power plant simulation are explained. Subsequently, various concepts for TES in steam power plants developed in the project will be presented and compared.

\section{Thermal Energy Storage (TES): Selection and Modelling}

Basically, there is a broad field of technology for TES but with a strongly varying degree of maturity. Prominent technologies are molten salt storage, Ruths steam accumulators and solid media heat storage: While molten salt storage facilities have already been commercially implemented on a GWh scale, Ruths steam accumulators, which are also commercially available, have so far only been implemented as relatively small buffer storage units. Solid media heat storage facilities have already been implemented on a power plant scale in other branches of industry but so far have only been implemented on a pre-commercial basis up to demonstration maturity in the power plant sector itself. In addition to these three technologies, which are suitable for large-scale use in power plants (see Figure 2), there are also other technologies from the field of latent heat storage and thermochemical storage [12]. While thermochemical storage units are still in the concept development stage, latent heat storage technology has been demonstrated pre-commercially and on a $1 \mathrm{MWh}$ scale for steam applications in industry and power plants [13].

Molten salt

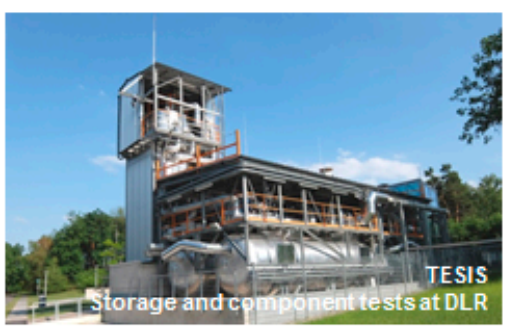

- Point of integration:

Steam cycle (indirect)

- Cost-effective and state of the art

- Suitable for mid temperature applications

- Suitable for rather large storage capacities
Solid media

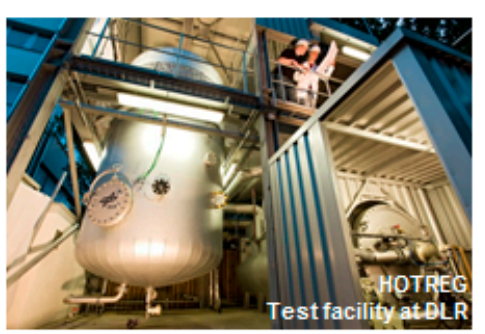

- Point of integration:

Flue gas path

- Low cost inventory options

- Suitable for high temperature applications

- Suitable for rather large storage capacities
Ruths (with PCM)

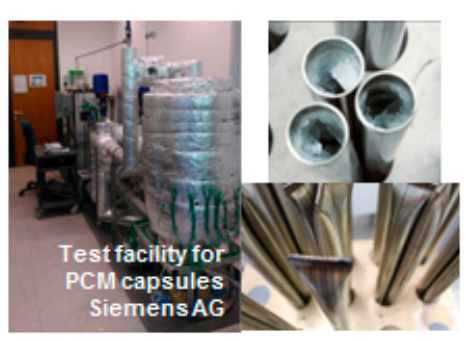

- Point of integration: Steam cycle (direct)

- Potential for improvement through integration of $\mathrm{PCM}$ capsules

- Highly dynamic

- Suitable for smaller storage capacities

Figure 2. Thermal energy storage technologies considered in the FLEXI-TES project.

\subsection{Molten Salt Storage Systems}

Today, molten salt technology is mainly used to store sensitive heat in solar thermal power plants. This technology makes it possible to generate electricity from sunlight continuously and independently of the supply. Worldwide, a capacity of almost $13 \mathrm{GWh}_{\mathrm{el}}$ [14] has been installed in this area of application, whereby typical systems can store approx. $1000 \mathrm{MWh}_{\text {th }}$ of heat. In non-solar applications, molten salt is also used as a heat transfer fluid in the chemical and metal industries [15]. The state of the art for large-scale storage is the pressureless two- or multi-tank system with at least one cold tank (usually approx. $290^{\circ} \mathrm{C}$ ) and at least one hot tank (usually approx. $390^{\circ} \mathrm{C}$ for parabolic trough power plants and up to $560^{\circ} \mathrm{C}$ for solar tower power plants) with molten salt [16]. Depending on the mixture of nitrate salts used, operating temperatures range from $150{ }^{\circ} \mathrm{C}$ to $560{ }^{\circ} \mathrm{C}$. It is important that the crystallization temperature has not fallen below. Therefore, in commercial processes, trace heating is always provided in the critical areas.

The size of the molten salt tanks can be roughly derived from the required capacity and temperature levels of the application. In addition to these capacity-dependent components, a molten salt storage 
system always also consists of power-dependent components such as pumps and heat exchangers. These can be dimensioned freely and independently of capacity and depend on the requirements of the process into which they are integrated. The maximum possible power consumption and output of molten salt storage systems is independent of the level in the tank and therefore constant at all times in contrast to solid media heat storage systems and Ruth's steam accumulators.

The thermal modelling of the molten salt storage tank can usually be carried out under the assumption of a constant spatial and temporal temperature distribution in the tanks. Thus, the storage tank can be described with one single zero-dimensional differential equation.

$$
\frac{d m_{\text {hot }}}{d t}=\frac{\dot{Q}_{\text {charge }}-\dot{Q}_{\text {discharge }}}{c_{p} \cdot\left(T_{\text {hot }}-T_{\text {cold }}\right)}
$$

Here, $m_{\text {hot }}$ is the mass of the hot salt in $\mathrm{kg}, \dot{Q}_{\text {charge }}$ the heat flow while charging, $\dot{Q}_{\text {discharge }}$ the heat flow while discharging in $\mathrm{kW}, c_{p}$ the specific heat capacity of the salt at mean temperature in $\mathrm{kJ} /(\mathrm{kg} \mathrm{K})$, $T_{\text {hot }}$ salt temperature in the hot tank in $\mathrm{K}, T_{\text {cold }}$ salt temperature in the cold tank in $\mathrm{K}$.

The system design is based on economic aspects: When integrating a molten salt storage tank into an existing process with a source heat flow at high temperature and a sink heat flow at lower temperature, the optimization variables can be, e.g., the temperature levels of hot and cold tanks $T_{\text {hot }}$ and $T_{\text {cold }}$. The costs of the storage components $C_{\text {Storage }}$ and the costs of the heat exchanger components $C_{\mathrm{HX}}$ Charge and $C_{\mathrm{HX}}$ Discharge are both dependent on the tank temperature $T_{\text {hot }}$ and $T_{\text {cold: }}$ :

$$
\begin{aligned}
C_{\text {Storage }} & =f\left(T_{\text {hot }}, T_{\text {cold }}\right) \\
C_{\text {HX Charge }} & =f\left(\text { LMTD }_{\text {Charge }}\right) \\
C_{\text {HX Discharge }} & =f\left(\text { LMTD }_{\text {Discharge }}\right) \\
\text { LMTD } & =f\left(T_{\text {hot }}, T_{\text {cold }}\right)
\end{aligned}
$$

An increase in the temperature of the hot tank and a decrease in the temperature of the cold tank lead to a better utilization of the existing storage material and thus to lower specific costs of the capacity-dependent components $C_{\text {Storage }}$. However, in contrast, the heat exchangers have to be designed for a smaller logarithmic mean temperature difference LMTD, which increases the associated costs $C_{\mathrm{HX}}$ Charge and $C_{\mathrm{HX}}$ Discharge. The optimum for $T_{\text {hot }}$ and $T_{\text {cold }}$ can be determined by parameter variation evaluating the total system costs.

\subsection{Solid Media Heat Storage}

Solid media heat storage systems are used today in numerous industrial processes in various temperature ranges. Examples are hot blast stoves or "Cowper" furnaces in the steel industry with upper process temperatures in the range of $1300-1600^{\circ} \mathrm{C}$, regenerators in the glass industry at high temperature levels of $1000-1300{ }^{\circ} \mathrm{C}$ and regenerative thermal oxidizer (RTO) systems in industrial air purification systems with upper process temperatures in the range of $800-1000{ }^{\circ} \mathrm{C}$. These are heat exchangers with a storage mass through which gases flow in a time offset countercurrent flow and in which the transferred heat is temporarily stored. These are passive components, i.e., no auxiliary energy is required directly in the storage. To overcome the pressure loss, however, it may be necessary to integrate a blower into the system. The field of application ranges from short-term storage, e.g., in industrial furnaces, to medium-term energy storage, e.g., in blast furnaces or in the exhaust gas cleaning of industrial processes. TES systems for solar power plants perform similar functions to compensate for daily fluctuations. Different operating conditions lead to different sizes and designs of the solid heat storage containers and the storage masses. The flowable solid media can consist of different materials, such as refractory materials, ceramics, natural stone or metals in different forms 
(packed beds or shaped bricks). The heat storage mass is usually housed in a container with internal thermal insulation. The choice of material for both the container and the thermal insulation depends on the heat storage material and the operating conditions (such as maximum temperature, pressure level or gas composition). The flow distribution is usually integrated into the container as an open volume.

When modelling the thermal behavior of solid media heat storage, it is necessary to take into account the dynamic character of the component, in contrast to the two-tank molten salt storage systems. This makes it necessary to calculate the temporal and local temperature distribution. The partial differential equations to describe the thermal behavior are based directly on heat balances over a single volume. In this case, the solid is not considered as a composition of individual independent bodies but as a continuous porous medium. The balance space extends over the inlet and outlet of the storage bed. In the case of packed beds, the heat conduction via the point-like contacts of the individual particles in the bed is modeled via effective values in the axial and radial directions according to [17]. According to [18], the differential equations of the heat balances in cylindrical coordinates for the fluid (6) and the solid phase (7) are

$$
\begin{gathered}
\varepsilon \rho_{F} c_{F}\left(\frac{\partial T_{F}}{\partial t}+w \frac{\partial T_{F}}{\partial z}\right)=\lambda_{F, z, e f f} \frac{\partial^{2} T_{F}}{\partial z^{2}}+\lambda_{F, r, e f f}\left[\frac{\partial^{2} T_{F}}{\partial r^{2}}+\frac{1}{r} \frac{\partial T_{F}}{\partial r}\right]+\alpha_{V} a_{V}\left(T_{S}-T_{F}\right)-k_{W} a_{W}\left(T_{F}-T_{0}\right) \\
(1-\varepsilon) \rho_{S} c_{S} \frac{\partial T_{S}}{\partial t}=\lambda_{S, z, e f f} \frac{\partial^{2} T_{S}}{\partial z^{2}}+\lambda_{S, r, e f f}\left[\frac{\partial^{2} T_{S}}{\partial r^{2}}+\frac{1}{r} \frac{\partial T_{S}}{\partial r}\right]+\alpha_{V} a_{V}\left(T_{F}-T_{S}\right)
\end{gathered}
$$

where $\varepsilon$ is the void fraction, $\rho$ the density in $\mathrm{kg} / \mathrm{m}^{3}, c$ the specific heat capacity in $\mathrm{J} /(\mathrm{kg} \mathrm{K}), \lambda$,eff the effective heat conduction in axial (z) and radial ( $\mathrm{r}$ ) directions in $\mathrm{W} /(\mathrm{m} \mathrm{K}), \alpha_{V}$ the heat transfer coefficient in $\mathrm{W} /\left(\mathrm{m}^{2} \mathrm{~K}\right), k_{W}$ the heat transfer coefficient through the shell surface of the storage tank in $\mathrm{W} /\left(\mathrm{m}^{2} \mathrm{~K}\right)$, $a_{V}$ the volume-specific heating surface in $\mathrm{m}^{2} / \mathrm{m}^{3}, a_{W}$ the volume-specific shell surface in $\mathrm{m}^{2} / \mathrm{m}^{3}$ and $w$ the fluid velocity in the bed in $\mathrm{m} / \mathrm{s}$.

With this arrangement it is assumed that the thermal resistance inside the solid is negligible and the heat transfer between the fluid and the solid is only determined by the heat transfer coefficient. However, depending on the thickness and thermal conductivity of the material, high heat transfer resistances sometimes occur in the solid. In order to consider this heat transfer in the storage bed itself and to develop a compact formulation of the heat balance equations, simplifications are made, which can be taken from, e.g., [19].

\subsection{Ruths-Type Steam Accumulator}

A Ruths-type steam accumulator is a pressure vessel filled with water. It is charged by the supply of (superheated) steam, which is provided, for example, by a turbine tap or a steam generator. The steam condenses when it is introduced into the storage tank, resulting in an increase in pressure, in (saturated steam) temperature and in water level in the tank. To discharge the storage tank, saturated steam is drawn off. The use of Ruths-type steam accumulators enables highly dynamic charging and discharging, i.e., immediate charging and discharging at high speed and high thermal output and is particularly suitable for processes where comparatively low storage capacities are required. Ruths-type steam accumulator units are currently used in power plants, for example at the PS10 solar power plant in Seville, Spain. The storage installed there has a capacity of $20 \mathrm{MWh}_{\text {th }}$ and is designed for a temperature of $250{ }^{\circ} \mathrm{C}$ at $40 \mathrm{bar}$ [20]. Other fields of application are also opening up in the textile industry, glass processing and metal production [21]. Within the framework of FLEXI-TES, the integration of a Ruths-type steam accumulator into a modern coal-fired power plant is being investigated.

Based on the assumption of a water-steam equilibrium in the storage tank, the states in the Ruths-type steam accumulator storage tank can be described sufficiently precisely using a single-phase model. For this purpose, the relevant enthalpy and mass balances are drawn up via the space between charging inlet and discharging outlet. A local resolution does not occur due to the assumed equilibrium state. The established balance equations can be differentiated and solved by suitable numerical 
methods. Thus, system specifications for discharge duration, mass flows and pressures can be used to determine solutions for storage tank sizes as well as temporal temperature and pressure curves in the storage tank.

The investment costs of Ruths-type steam accumulator systems depend largely on the storage volume required for the capacity. For this reason, the FLEXI-TES project is investigating the combination of a Ruths-type steam accumulator system with capsules filled with phase change material (PCM). By selecting a suitable PCM whose melting temperature lies between the saturated steam temperatures of the lower and upper operating pressure of the Ruths-type steam accumulator, a significant reduction of the necessary storage volume can be achieved at a given storage capacity. Central parameters in the selection of a suitable PCM are therefore the melting temperature range, the melting enthalpy, the specific heat capacity and the thermal conductivity.

On the basis of these parameters, the input and output of sensitive and latent heat can be taken into account when modelling a Ruths-type steam accumulator system with integrated PCM. The balance equations of the Ruths-type steam accumulator are supplemented by the PCM. Thus, for example, the heat flow and the radial temperature curve within the individual PCM capsules can be calculated.

\section{Stationary Power Plant Simulation}

The thermodynamic evaluation of the integration concepts of thermal energy storage systems was carried out in the first project phase on the basis of a stationary power plant model in EBSILON ${ }^{\circledR}$ Professional. This includes a detailed illustration of the steam generator, in which each individual heating surface is illustrated and calculated, as well as the modelling of the closed water/steam cycle (see Figure 3). The usage of a detailed stationary power plant model makes it possible to identify the effects of the TES integration on the power plant process (e.g., in the form of changed mass flows, pressures and temperatures) as well as the achievable flexibility potential.

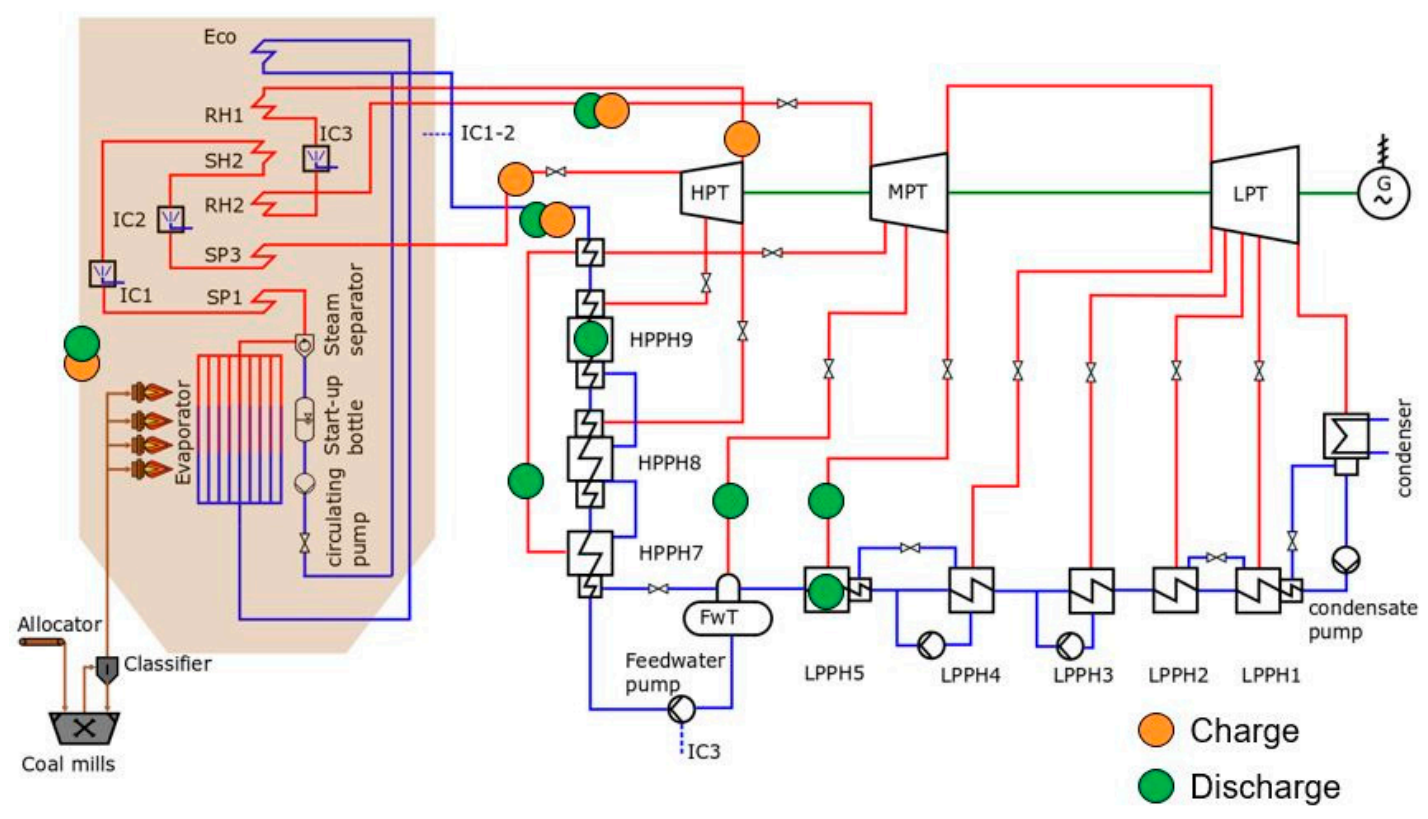

Figure 3. Thermal circuit diagram of the stationary power plant model with charging and discharging points of all storage concepts considered in the first project phase $($ Eco $=$ Economizer, FwT $=$ Feedwatertank, G = Generator, HPT = High Pressure Turbine, HPPH = High Pressure Preheater, IC = Intercooler, $\mathrm{LPPH}=$ Low Pressure Preheater, $\mathrm{LPT}=$ Low Pressure Turbine, MPT $=$ Medium Pressure Turbine, $\mathrm{RH}=$ Reheater, $\mathrm{SH}=$ Superheater, $\mathrm{SP}=$ Steam preheater).

The power plant model represents the current state of the art of hard coal-fired power plants with live steam temperatures of approx. $600^{\circ} \mathrm{C}$. With minor differences in thermal circuit diagrams and 
design, the power plant model used thus represents a technology class of hard coal-fired power plants based on the concept study for the reference power plant North Rhine-Westphalia [22]. Built power plants with comparable parameters include Walsum 10, Westfalen E, Moorburg A/B, RDK 8, Maasvlakte 3 and the Trianel power plant in Lünen.

Table 1 shows an overview of the main parameters of the stationary power plant model at the design point. A value of $20 \%$ of the net output is considered for the minimum load, in which the charging of an integrated TES is particularly suitable.

Table 1. Process parameters of the stationary power plant model.

\begin{tabular}{ccc}
\hline & Gross output & $800 \mathrm{MW}$ \\
Nlock Data & Minimum load & $739 \mathrm{MW}$ el \\
& Gross efficiency & $20 \% \mathrm{P}_{\mathrm{n}}$ \\
& Net efficiency & $49.8 \%$ \\
& Design type & $46.0 \%$ \\
\hline \multirow{3}{*}{ Steam generator } & Live steam mass flow & $592 \mathrm{~kg} / \mathrm{s}$ \\
& Live steam parameters & $280 \mathrm{bar} / 600^{\circ} \mathrm{C}$ \\
& Hot reheat section parameter & $60 \mathrm{bar} / 620^{\circ} \mathrm{C}$ \\
\hline
\end{tabular}

\section{Development of Storage Integration Concepts}

In order to identify suitable TES integration concepts, a broad portfolio of a total of 15 storage solutions was developed. These have been grouped into six concepts divided by storage technology and integration points.

Most concepts use steam from the cold reheat to charge the TES and a discharge into the feedwater preheater. Systems with steam temperatures above $500^{\circ} \mathrm{C}$ and concepts in the flue gas path have also been developed.

For the concept portfolio, the potentials of load increase (discharging) or load reduction (charging) were first determined taking into account typical limitations of coal-fired steam generators, steam turbines and main components of the water-steam cycle. These results were then used to calculate the electricity to electricity efficiency of the storage concepts. Based on exemplary storage capacities of $15 \mathrm{~min}$ or $120 \mathrm{~min}$, the storage facilities were then pre-designed, and the investment costs for the storage facility and its integration were calculated using consistent cost models.

To identify the lead concepts described below, an evaluation method was finally developed and applied, which is essentially based on two established management instruments in product development, namely, Quality Function Deployment (QFD) and Failure Mode and Effect Analysis (FMEA) $[23,24]$. This analysis approach makes it possible to weigh many evaluation criteria against each other in terms of importance and to quantify their fulfilment for different concepts. The concept evaluation carried out in FLEXI-TES distinguishes between economic and technical requirements. The following essential criteria were taken into account:

- Economic requirements: low investment costs, high additional contribution margins, low operating costs, low system integration costs, retrofittability in existing plants.

- Technical requirements: high electricity to electricity efficiency, high minimum load reduction due to TES charging, high overload due to TES discharge, ability to be integrated into the power plant system, ability to provide balancing energy, high influence on load change rate, ability to improve start-up and shut-down processes, high potential for multiple uses.

The following three concepts were finally identified as lead concepts, each using different storage technologies (molten salt storage system, solid media heat storage and Ruths-type steam accumulator). There are various reasons for this choice, but in most cases, the storage of heat that is as exergy-rich as possible is the most effective and is specifically the most economical. The disadvantages of integration 
at process points with high temperatures and pressures were included in the decision but do not usually weigh as heavily as the energetic advantages. The respectively selected storage technologies represent the best and most adapted technology in terms of process parameters and costs for the respective integration location.

\subsection{Brief Description: HRH-HPPH9_indirectly (Molten Salt Storage)}

The charging is carried out by steam extraction from the hot reheat (HRH). After heat transfer, the cooled steam is returned to the overflow line between the medium-pressure turbine (MPT) and the low-pressure turbine (LPT). The reduction of the HRH steam mass flow leads to a lower throughflow of the MPT, accompanied by a decrease in the net output.

During discharging, the heat temporarily stored in the TES is used to achieve HP preheating via an additional heat exchanger or to bypass the last HP preheater (HPPH9). By bypassing the last HP preheater, no or a lower extraction steam mass flow is required at the extraction at the high-pressure turbine (HPT). An additional steam mass flow therefore flows into the downstream turbine stages of the HPT, MPT and LPT, generating additional electrical power.

The storage system is based on two molten salt tanks, hot tank and cold tank, each with one pump. The coupling with the power plant process is realized by two heat exchangers; therefore, it is an indirect storage system.

When designing the molten salt storage system, sensitivity studies on different hot and cold tank temperatures were carried out under given boundary conditions and optimized with regard to minimum investment costs.

\subsection{Brief Description: CRH/LS-HPPH7_directly (Ruths + PCM)}

Charging takes place in the upper load range of the power plant by steam extraction from the cold reheat (CRH). The extracted steam is fed to a Ruths-type steam accumulator, in which the pressure, the (saturated steam) temperature and the filling level rise during charging. The reduction of the CRH steam mass flow leads to a lower flow of MPT and LPT, accompanied by a decrease in the net capacity. Due to the CRH pressure dropping in the direction of partial load, an additional charging with live steam is provided in the lower load range. Without this additional integration point, charging at minimum load with subsequent discharge at full load is not possible.

During discharging, saturated steam is discharged of the Ruths-type steam accumulator. This replaces the original tapping of the first HP preheater (HPPH7). As a result, there is an additional steam mass flow in the rear part of the MPT and in the LPT, which leads to an increase in the net output.

The storage system is based on a Ruths-type steam accumulator with or without integrated PCM. Since the working medium of the power plant process is stored or retrieved, it is a direct storage system.

The pressure vessel was designed both for the classic case without integrated PCM and for the innovative approach of integrating PCM capsules. In the pressure range between the CRH (approx. 60 bar) and tapping to the HPPH7 (approx. 25 bar), $\mathrm{LiNO}_{3}$ was identified as a suitable PCM for which a melting temperature of approx. $254{ }^{\circ} \mathrm{C}$ and a melting enthalpy of approx. $360 \mathrm{~kJ} / \mathrm{kg}$ can be assumed [25].

\subsection{Brief Description: Flue gas-Air_indirectly (Solid Media Heat Storage)}

Charging takes place by removing hot flue gas in the area of the evaporator or above the radiation zone in the gas path of the boiler. The heat of the hot flue gas is then transferred almost isobarically to the TES. The cooled flue gas emerging from the TES system is then returned to the main flue gas stream prior to flue gas cleaning.

During discharge, an additional air mass flow is sucked in from the surroundings, heated via the TES and coupled into the flue gas flow of the steam generator in the area of the evaporator or above the radiation zone. Due to the additional thermal output of the flue gas flow within the tube bundle 
heating surfaces, higher live steam mass flows and thus higher electrical outputs can be achieved. The TES is based on solid media.

When designing the solid media heat storage, extensive variation studies on various parameters, such as material (bricks made of refractory materials, honeycombs and spheres made of ceramics) and geometries of the storage materials (different specific heat surfaces and void fraction) and the tanks (different height to diameter ratio), were carried out under specified boundary conditions (inlet temperature, pressure and mass flow) and optimized with regard to minimum investment costs.

\section{Comparative Evaluation of Storage Integration Concepts}

Depending on the concept under consideration and the current load point of the power plant, the three identified lead concepts show different changes in the net capacity during charging and discharging as well as different TES storage efficiencies.

Figure 4 shows in this context the change in the net capacity during charging and discharging processes of the TES lead concepts in full load and minimum load of the power plant. The charging and discharging is partly carried out with different thermal capacities, which were determined in advance under consideration of limitations from the power plant process (e.g., minimum flow through the steam generator and steam turbine, maximum possible overload of the steam generator). For example, in the HRH-HPPH9_indirectly concept, a maximum possible thermal load capacity of $28 \mathrm{MW}_{\text {th }}$ is available for charging at the minimum load due to the minimum flow rate of the MP turbine to be taken into account, accompanied by a reduction of the net capacity by $25 \mathrm{MW}_{\mathrm{el}}$. Charging at full load can take place with a significantly higher thermal output of $80 \mathrm{MW}_{\text {th }}$, which consequently results in a stronger effect on the net output of $74 \mathrm{MW}_{\mathrm{el}}$. Load-dependent thermal powers also come into play during the discharge, since, for example, the discharge in the direction of the high-pressure preheating section can at most replace the respective bleed steam at the integration point. Since the mass flows at the tappings decrease in the direction of partial load during normal operation, the achievable increase in net output during discharge also decreases significantly in the case of the two lead concepts concerned as the load on the power plant decreases.

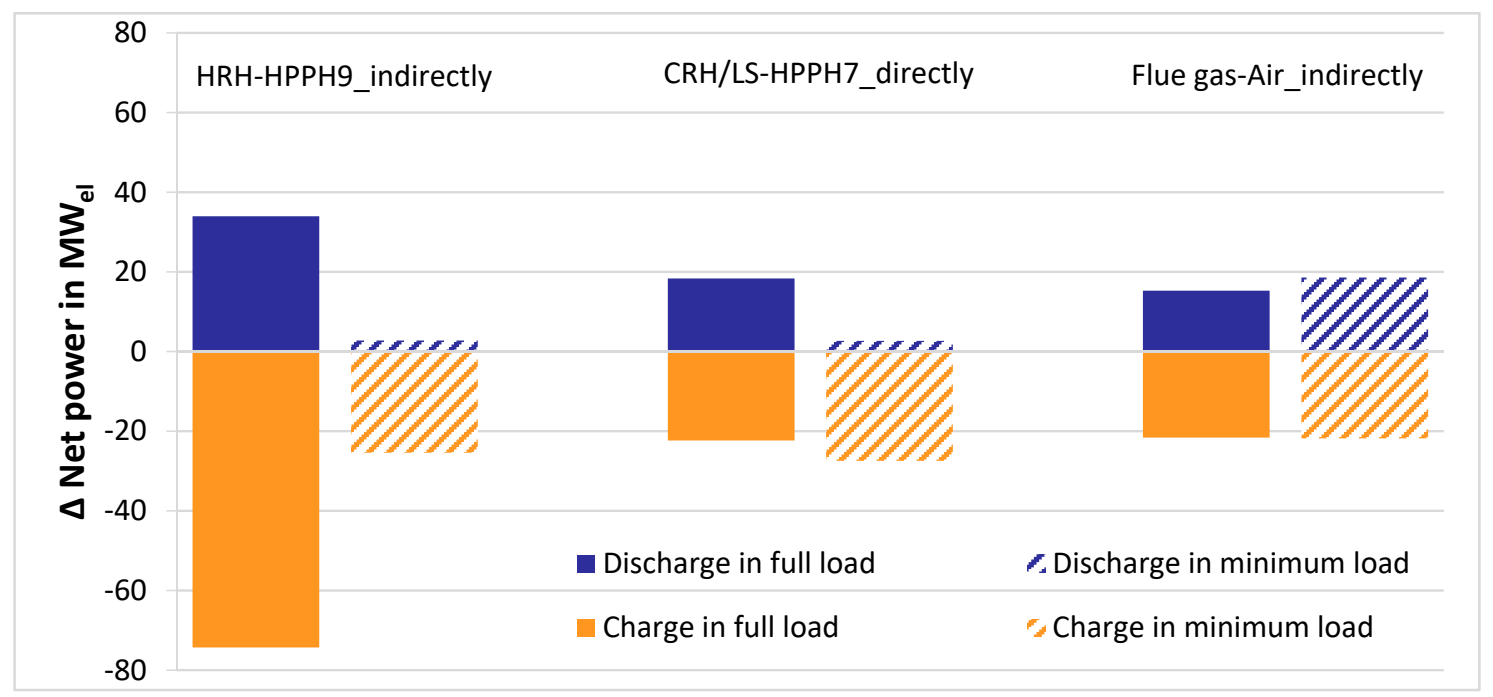

Figure 4. Change in net output during charging and discharging processes of the TES lead concepts at different operating points of the power plant.

Overall, the lead concepts examined show a reduction of the minimum load in the order of 22 to $28 \mathrm{MW}_{\mathrm{el}}$ or $3 \%$ to $4 \%$ of the net capacity. During discharge at full load, a load increase of 15 to $34 \mathrm{MW}_{\mathrm{el}}$ or $2 \%$ to $5 \%$ of the net capacity is possible. 
The parameters determined for charging and discharging the TES lead concepts using the stationary power plant model can also be used to calculate TES efficiency. The TES efficiency is determined by the so-called round-trip efficiency. In this "electricity to electricity" evaluation, the additional net output during discharging $\Delta \mathrm{P}_{\text {el,discharging }}$ in $\mathrm{W}$ is set in relation to the reduction of the net output

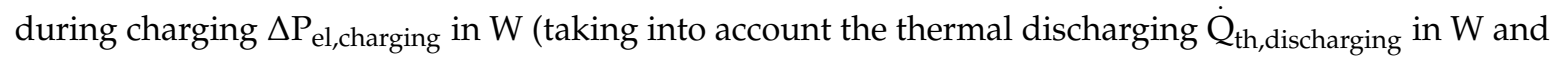
charging capacities $\dot{\mathrm{Q}}_{\mathrm{th} \text {,charging }}$ in $\left.\mathrm{W}\right)$.

$$
\eta_{\mathrm{TES}}=\frac{\Delta \mathrm{P}_{\mathrm{el}, \text { discharging }}}{\Delta \mathrm{P}_{\mathrm{el} \text {, charging }}} \cdot \frac{\dot{\mathrm{Q}}_{\mathrm{th} \text {,hharging }}}{\dot{\mathrm{Q}}_{\mathrm{th}, \text { discharging }}}
$$

For the three TES lead concepts, the electricity-to-electricity efficiencies shown in Figure 5 result. Due to the load-dependent behavior of the storage concepts, a distinction is made here between the two leading operating strategies. The first operating strategy comprises a storage cycle consisting of charging and discharging at full load of the power plant or steam generator (fully filled bars in Figure 5). This operating strategy can be used, for example, to exploit price peaks and price valleys at a high electricity price level above the variable costs of a specific power plant or to provide control power. The second operating strategy comprises a storage cycle with charging at the minimum load and subsequent discharging at full load (hatched bars in Figure 5). This operating strategy is characterized by the charging (low residual load and exchange electricity prices) and a subsequent provision of overload (high residual load and exchange electricity prices) in order to reduce the electrical minimum load and plays a relevant role especially in TES concepts with storage durations in the range of several hours.

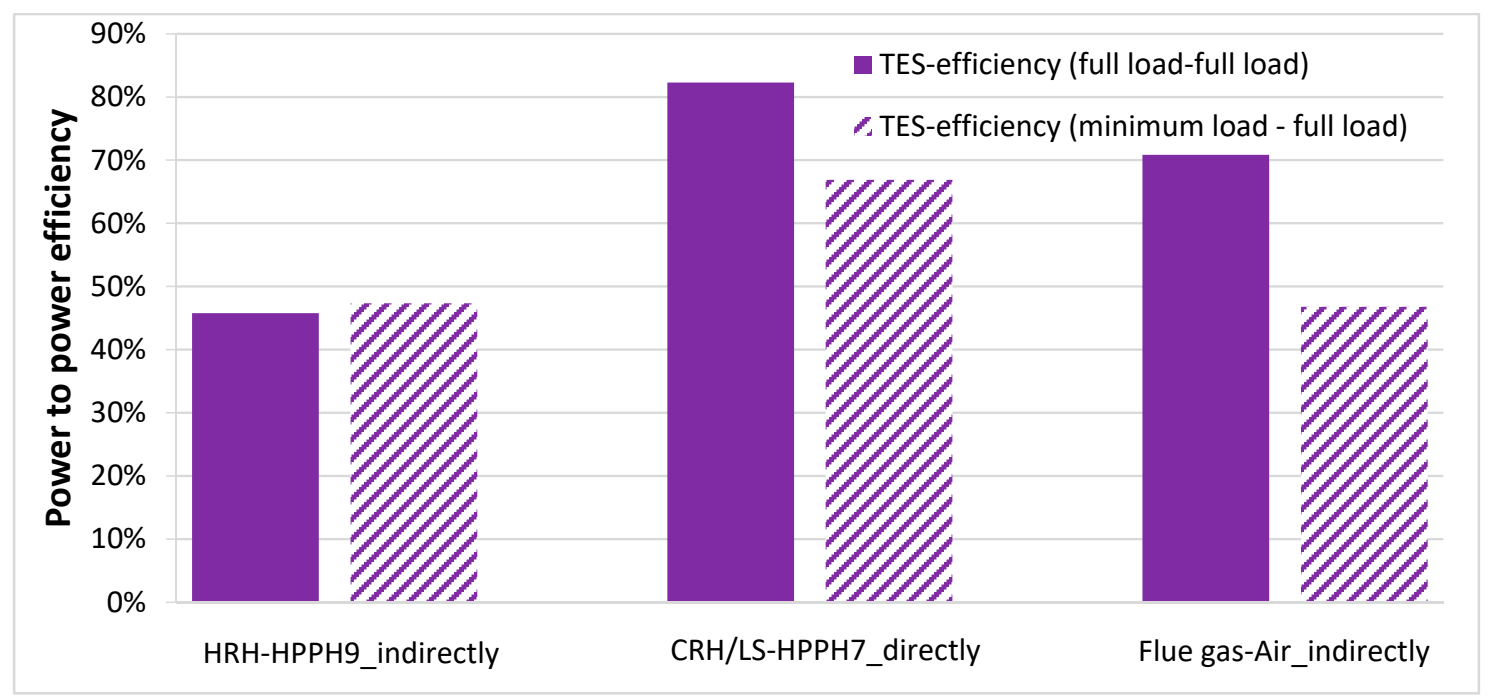

Figure 5. Efficiencies of the TES lead concepts for the two operating strategies full load/full load and minimum load/full load.

The TES efficiencies determined from the combination of a stationary power plant model and integrated heat storage units range between $46 \%$ and $82 \%$ and depend to a large extent on the integration points and the exergy losses between the integration points.

The HRH-HPPH9_indirectly concept based on the molten salt has a TES efficiency of approx. $47 \%$, which is almost independent of the power plant load points under consideration. The CRH/LS-HPPH7_directly concept results in a round trip efficiency of $82 \%$ for the full load/full load operating strategy. Due to the charging of the Ruths-type steam accumulator with higher-quality live steam in the minimum load, the TES efficiency for the minimum load/full load operating strategy is 
reduced to $67 \%$. The Flue gas-Air_indirectly solid media heat storage shows achievable TES efficiencies of between $47 \%$ and $71 \%$, depending on the operating strategy.

The discussion of the results obtained here with those published in the few studies available in the literature is difficult due to the different plants and boundary conditions. A direct comparability is only given for one concept described by Li et al. [6]. As in the HRH-HPPH9_indirectly concept, steam is extracted from the hot reheat pipeline. However, the thermal energy is not transferred to a molten salt storage system, but to PCM storage. In addition, the cold mass flow is then fed to the condenser and not to the overflow line between the medium- and low-pressure turbines. The calculated values for the output of $3.9 \%$ of the nominal output and for the efficiency of around $43 \%$ correspond to the order of magnitude of the results presented here. The use of a PCM storage unit is viewed critically by the authors, as the technology is not state of the art on such a scale and integration at this point in the power plant requires the storage of high amount of sensitive heat. The supply to the condenser was also considered for this concept in the project, but the efficiency is somewhat lower due to the poorer thermodynamic integration and was therefore not pursued further.

\section{Summary}

The expansion of renewable energies is increasing the fluctuations in electricity generation. In order to cope with these fluctuations and ensure grid stability, conventional power generation technologies must be able to adapt flexibly to the fluctuating residual load. For conventional power plants, the integration of thermal energy storage (TES) into the power plant process opens up a promising option for meeting future technical requirements in terms of flexibility while at the same time improving economic efficiency.

In the FLEXI-TES joint project, the flexibilization of coal-fired steam power plants through the integration of TES is being investigated. The selection of suitable storage technologies, their integration and design, supplemented by stationary power plant simulations, were the main tasks of the concept phase, in which many different integration concepts were developed and evaluated. In the end, three lead concepts were identified, which will be elaborated in detail in the course of the project. These concepts differ with regard to the integration points in the power plant process as well as in the different storage technologies provided.

The comparative evaluation of the storage integration concepts within the performed stationary system simulations showed that, depending on the concept under consideration and the currently available load point of the power plant, these have different changes in the net capacity during charging and discharging as well as different TES storage efficiencies. All in all, the lead concepts examined show a reduction of the minimum load in the order of $3 \%$ to $4 \%$ of the net capacity. During discharge at full load, a load increase of $2 \%$ to $5 \%$ of the net capacity is possible. The achievable electricity to electricity storage efficiencies are between $47 \%$ and $82 \%$, depending on the concept and operating strategy.

In the second phase of the FLEXI-TES project, the focus will be on further refining storage concepts, cost reduction approaches and pilot plant trials for the individual storage technologies. This will be flanked by simulation studies of the TES integration with a dynamic power plant model. In addition, based on energy market scenarios for the year 2030, the power plant and storage use based on economic principles will be determined in order to estimate the cost-effectiveness of retrofitting conventional existing and new power plants with TES systems. At the same time, a detailed investigation of the integration of the TES lead concepts into a reference plant selected by the project consortium will be carried out.

Author Contributions: This paper was mainly written by M.K. under support from T.L. M.K. is the project leader of the FLEXI-TES project and supplied the part of solid media heat storage. F.K. provided the part of molten salt storage systems and P.K. supplied the Ruths-type steam accumulator part. The Ruths-type steam accumulator system with integrated PCM was the task of C.M. The power plant simulation and the comparative evaluation were mainly carried out by S.M. All authors have read and agreed to the published version of the manuscript. 
Funding: This project has received funding from the German Federal Ministry for Economic Affairs and Energy (BMWi) under grant agreement No. 03ET7055.

Conflicts of Interest: The authors declare no conflict of interest. The funders had no role in the design of the study; in the collection, analyses, or interpretation of data; in the writing of the manuscript, or in the decision to publish the results.

\section{References}

1. International Energy Agency. World Energy Outlook; International Energy Agency: Paris, France, 2017.

2. Krüger, M.; Dreißigacker, V.; Meier, S.Z.u.H.-J. Flexibilisierung von Kohlekraftwerken durch Integration von Wärmespeichern: Ergebnisse des Verbundvorhabens Partner-Dampfkraftwerk; Kraftwerkstechnisches Kolloquium: Dresden, Germany, 2015.

3. Beckmann, G.; Viktor, P. Thermal Energy Storage, Wien; Springer: New York, NY, USA, 1984.

4. Goldstern, W. Dampfspeicheranlagen; Springer: Berlin/Heidelberg, Germany, 1963.

5. Jentsch, N.; Jochmann, A.; Kratzsch, A.; Braun, S. Auslegung von Energiespeichern und Integration in konventionelle Bestandskraftwerke; Kraftwerkstechnisches Kolloquium: Dresden, Germany, 2013.

6. Li, D.; Wang, J. Study of supercritical power plant integration with high temperature thermal energy storage for flexible operation. J. Energy Storage 2018, 20, 140-152. [CrossRef]

7. Drost, M.K.; Antoniak, Z.I.; Brown, D.R.; Sathyanarayana, K. Thermal Energy Storage for Power Generation; Pacific Northwest Laboratory: Washington, DC, USA, 1989.

8. Cao, R.; Lu, Y.; Yu, D.; Guo, Y.; Bao, W.; Zhang, Z.; Yang, C. A novel approach to improving load flexibility of coal-fired power plant by integrating high temperature thermal energy storage through additional thermodynamic cycle. Appl. Therm. Eng. 2020, 173, 115225. [CrossRef]

9. Lehmkuhl, C.; Stork, R. Praktische Erfahrungen bei Planung, Bauausführung und Inbetriebnahme eines thermischen Energiespeichers im Großkraftwerk Mannheim; Kraftwerkstechnisches Kolloquium: Dresden, Germany, 2014.

10. Niehörster, K. Wärmespeicher-effizientere Versorgung durch KWK-Anlagen mit flexibler Steuerung. Energ. Tagesfr. 2015, 65, 66-67.

11. Forschungszentrum Jülich GmbH [Online]. Available online: https://www.fz-juelich.de/SharedDocs/ Meldungen/ETN/DE/StortoPower.html (accessed on 27 April 2020).

12. Tamme, R.; Laing, D.; Steinmann, W.-D.; Bauer, T. Thermal Energy Storage. In Encyclopedia of Sustainability Science and Technology; Springer: New York, NY, USA, 2012.

13. Johnson, M.; Vogel, J.; Hempel, M.; Dengel, A.; Seitz, M.; Hachmann, B. High Temperature Latent Heat Thermal Energy Storage Integration in a Co-gen Plant. Energy Procedia 2015, 73, 281-288. [CrossRef]

14. REN21. Renewables 2018. Global Status Report; REN21 Secretariat: Paris, France, 2018.

15. Carling, R.; Mar, R. Industrial use of Molten Nitrate/Nitrite Salts; Sandia National Labs.: Livermore, CA, USA, 1981.

16. Herrmann, U.; Kelly, B.; Price, H. Two-tank molten salt storage for parabolic trough solar power plants. Energy 2004, 29, 883-893. [CrossRef]

17. Wakao, N.; Kaguei, S. Heat and Mass Transfer in Packed Beds; Gordon and Breach Science Publishers: New York, NY, USA; London, UK; Paris, France, 1982.

18. Ismail, K.A.R.; Stuginsky, R., Jr. A parametric study on possible fixed bed models for pcm and sensible heat storage. Appl. Therm. Eng. 1999, 19, 757-788. [CrossRef]

19. Hirsch, T. SolarPACES Guideline for Bankable STE Yield Assessment; IEA Technology Collaboration Programme SolarPACES: Tabernas, Spain, 2017.

20. Osuna, R.; Olavarría, R.; Morillo, R.; Sánchez, M.; Cantero, F.; Fernández-Quero, V.; Robles, P.; López, T.; Esteban, A.; Céron, F.; et al. PS10, Construction of a 11MW Solar Thermal Tower Plant in Seville, Spain; SolarPACES: Seville, Spain, 2006.

21. Stevanovic, V.D.; Maslovaric, B.; Prica, S. Dynamics of steam accumulation. Appl. Therm. Eng. 2012, 37, 73-79. [CrossRef]

22. PowerTech eV, V.G.B. Konzeptstudie Referenzkraftwerk Nordrhein-Westfalen (RKW NRW); VGB PowerTech Service GmbH: Essen, Germany, 2004.

23. Akao, Y. Quality Function Deployment: Integrating Customer Requirements into Product Design; Productivity Press: Cambridge, UK, 1990. 
24. Akao, Y.; Mizuno, S. QFD: The Customer-Driven Approach to Quality Planning and Deployment; Asian Productivity Organisation: Tokyo, Japan, 1994.

25. Tamme, R.; Bauer, T.; Buschle, J.; Laing, D.; Müller-Steinhagen, H.; Steinmann, W.D. Latent heat storage above $120^{\circ} \mathrm{C}$ for applications in the industrial process heat sector and solar power generation. Int. J. Energy Res. 2008, 32, 264-271. [CrossRef] 